\title{
Effect of Heat Treatment on the Pore Structure and Drying Shrinkage Behavior of Hydrated Cement Paste
}

\author{
Jeffrey J. Thomas ${ }^{\star, \dagger}$ and Hamlin M. Jennings ${ }^{\star, \dagger, *}$ \\ Department of Civil and Environmental Engineering and Department of Materials Science and Engineering, \\ Northwestern University, Evanston, Illinois 60208
}

\begin{abstract}
The effect of a short heat treatment on hydrated cement paste has been investigated by measuring the weight and length changes of specimens as they undergo various combinations of heating, drying, and resaturation. Heating a cement paste to $60^{\circ} \mathrm{C}$ coarsens the capillary pore system, decreases the volume of mesopores, and increases the degree of polymerization of the silicates. In addition, the saturated weight of the paste is permanently decreased by a heat treatment. This weight loss can be explained by conversion of bound hydroxyl groups into liquid water during polymerization of the C-S-H gel phase. These experiments help reconcile and interpret published results describing the properties of cement cured at various temperatures, the effects of a short heat treatment on cement paste, and the thermal expansion behavior of saturated and dry cement paste.
\end{abstract}

\section{Introduction}

$\mathrm{T}$ HE hydration temperature has a significant impact on the hardening of cement paste and concrete. The activation energy for the rate of early hydration is $\sim 35 \mathrm{~kJ} / \mathrm{mol} ;{ }^{1}$ therefore, higher curing temperatures greatly accelerate the rate of hydration and strength development during the first $12-24 \mathrm{~h}$ after mixing. However, elevated-temperature curing decreases the long-term strength and increases permeability and, thus, is generally considered undesirable. ${ }^{2}$ The lower strength of concrete placed during hot summer conditions has been documented recently. ${ }^{3}$

Because the hydration of cement is strongly exothermic, the internal temperature of a structure can be significantly higher than the surface, and higher ambient temperatures lead to a greater internal temperature increase. Therefore, although field concrete is rarely placed at ambient temperatures greater than $\sim 40^{\circ} \mathrm{C}$, internal temperatures of large structures can easily reach or exceed $60^{\circ} \mathrm{C}$. Therefore, consideration of the effects of high curing temperatures and of heat treating should not be limited to precast steam-cured materials, which are generally cured at anywhere from $40^{\circ}$ to $100^{\circ} \mathrm{C}$.

Exposing a hardened cement paste cured near room temperature to an elevated temperature for a relatively short period of time affects the subsequent drying and creep behavior, as first reported by Parrott. ${ }^{4,5}$ After such a heat treatment, the total shrinkage on drying to a given relative humidity $(\mathrm{RH})$ is decreased, although the amount of water lost may be greater than the control. After resaturation, it is observed that the irreversible component of drying shrinkage is significantly decreased, while the reversible

G. Scherer-contributing editor

Manuscript No. 187678. Received May 29, 2001; approved October 27, 2001

Supported by the National Science Foundation under Contract No. CMS-007-0922.

${ }^{*}$ Member, American Ceramic Society.

Department of Civil and Environmental Engineering.

*Department of Materials Science and Engineering. component is relatively unaffected. Basic creep and drying creep are also decreased by heat treatment. ${ }^{4}$ These effects of heat treatment have been attributed to a coarsening of the pore structure similar to that observed on first drying of cement paste and are associated with increased silicate polymerization in the $\mathrm{C}-\mathrm{S}-\mathrm{H}^{\S}$ gel phase. $^{5}$

On heating, cement paste exhibits complex thermal expansion behavior that varies with time and with the moisture state of the pore system. ${ }^{6}$ Close to saturation, paste undergoes a large initial expansion on heating and then slowly contracts back to a more modest expansion. ${ }^{6,7}$ This behavior, also observed in pure gels, ${ }^{8}$ can be explained by the fact that the liquid water in the pore system undergoes much greater thermal expansion than the solid matrix. ${ }^{8,9}$ After initial expansion, the water flows out of the solid, causing a contraction back toward the original length. Recently, it has been shown that the kinetics of this behavior provides a promising new way to measure the permeability of cement paste. ${ }^{10,11}$ When partially dried cement paste is heated, the length change behavior is quite different from that of saturated paste. The paste expands initially on heating and then continues to expand, ${ }^{6}$ a phenomenon that is not well understood.

In this article, we again show that heating of cement paste causes a change in the pore-size distribution, with an increase in capillary porosity and a decrease in mesoporosity. A collection of new experiments and measurements show that the most likely interpretation of all reported results (including the expansion of dried paste on heating) is that heating cement paste causes a densification of the C-S-H gel phase associated with increased polymerization of the silicates and the release of liquid water.

\section{Experimental Procedure}

Type I portland cement (Lehigh Portland Cement Co., Allentown, PA) was cast into plastic molds at a water/cement $(w / c)$ ratio of 0.45 and hydrated under limewater at room temperature to form bars measuring $25 \mathrm{~cm} \times 2.5 \mathrm{~cm} \times 2.5 \mathrm{~cm}$. For most experiments, these bars were cut into smaller prisms measuring $17 \mathrm{~cm} \times 2.5$ $\mathrm{cm} \times 0.5 \mathrm{~cm}$. For experiments that involved length change measurements, brass endpoints were affixed to the prisms using waterproof epoxy. A white portland cement with a low aluminates content (US Gypsum Co., Chicago, IL) was used to duplicate the results of some of the weight-loss experiments. Table I gives the compositions of the cements used.

Heat treatments were performed using a programmable water bath. Specimens were placed into a plastic container of limewater floating in the bath, unless otherwise noted. Because the temperature at different locations within a water bath could vary by a few degrees, the actual temperature was measured using a thermometer placed next to the specimen. These experiments used a maximum programmed temperature of $60^{\circ} \mathrm{C}$ to avoid secondary hightemperature reactions, such as the decomposition of ettringite into monosulfate, which would hamper interpretation of the results.

${ }^{\S}$ Cement notation used throughout: $\mathrm{C}$ is $\mathrm{CaO} ; \mathrm{S}$ is $\mathrm{SiO}_{2} ; \mathrm{H}$ is $\mathrm{H}_{2} \mathrm{O}$, and $\mathrm{A}$ is $\mathrm{Al}_{2} \mathrm{O}_{3}$. 
Table I. Composition of Cements

\begin{tabular}{lcc}
\hline & \multicolumn{2}{c}{ Composition (wt\%) } \\
\cline { 2 - 3 } \multicolumn{1}{c}{ Mineral } & OPC & White cement \\
\hline $\mathrm{C}_{3} \mathrm{~S}$ & 58 & 72 \\
$\mathrm{C}_{2} \mathrm{~S}$ & 16 & 17 \\
$\mathrm{C}_{3} \mathrm{~A}$ & 10 & 5 \\
$\mathrm{C}_{4} \mathrm{AF}$ & 7 & 1 \\
$\mathrm{Na}_{2} \mathrm{O}+\mathrm{K}_{2} \mathrm{O}$ & 1.1 & 0.7 \\
Free lime & 0.5 & 1.6 \\
\hline
\end{tabular}

Experiments that could be significantly affected by such a change in the aluminate phases were repeated using the lower- $\mathrm{C}_{3} \mathrm{~A}$ white cement, and, on one occasion, using a $\mathrm{C}_{3} \mathrm{~S}$ paste.

Length changes were measured using a stand micrometer, and each measurement was normalized by measuring the length of a room-temperature brass control rod immediately afterward. During the thermal expansion measurements of saturated paste, the prisms were removed from the water bath and measured as quickly as possible. This led to scatter in the measurements, and these experiments were repeated at least once. For the experiments measuring length changes caused by heat treatment of dried paste, the prisms were cooled to room temperature under sealed conditions before each measurement to avoid convoluting microstructural changes with thermal expansion. Weight measurements were made using an electronic balance. Saturated specimens were weighed in the surface-dry condition. Drying experiments were conducted by placing the specimens in a drying room maintained at $50 \% \mathrm{RH}$ and $20^{\circ} \mathrm{C}$. Resaturation was in limewater.

\section{Results and Discussion}

\section{(1) Heating of Saturated Paste}

Figure 1 shows a typical result for the length change of a $28 \mathrm{~d}$ old prism heated rapidly by placing it directly into a $60^{\circ} \mathrm{C}$ water bath. The prism underwent a large initial expansion during the first few minutes, then contracted more slowly, and reached a steadystate strain value of $3.4 \times 10^{-4}$ after $\sim 20 \mathrm{~min}$. This result is in good qualitative agreement with the results of Ai and Young, ${ }^{7}$ who have conducted similar measurements using a more precise measurement technique. This type of expansion behavior has been described quantitatively by Scherer and co-workers. ${ }^{8,10}$ When the pore fluid expands more quickly than it can flow out of the specimen, the increased internal pressure causes expansion, which is then relieved as the water continues to flow out at the surface. The prism shown in Fig. 1 was cooled back to $20^{\circ} \mathrm{C}$ very slowly,

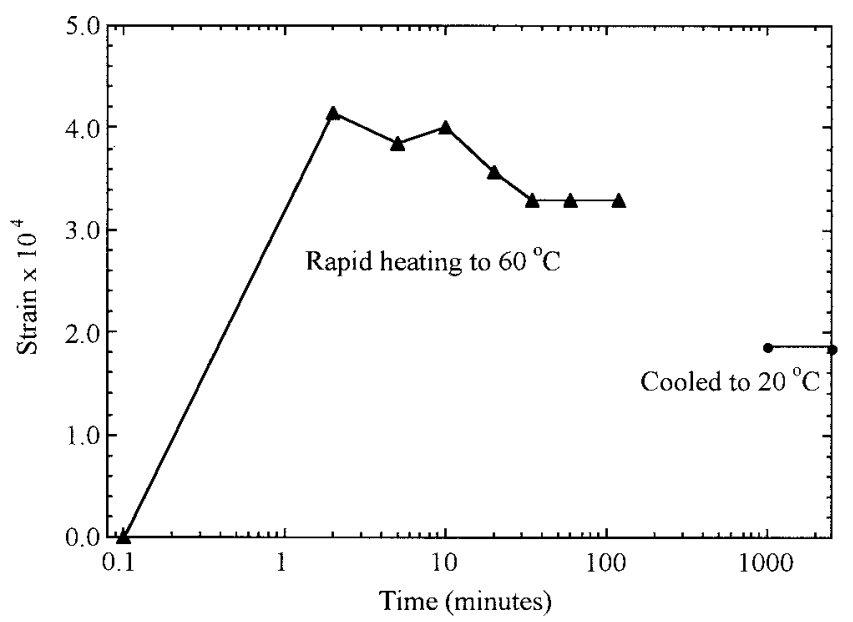

Fig. 1. Length change of a prism heated rapidly to $60^{\circ} \mathrm{C}$ and then cooled slowly back to $20^{\circ} \mathrm{C}$. and this experiment resulted in a permanent expansive strain of $\sim 2 \times 10^{-4}$.

Figure 2 shows the results of a companion experiment conducted by heating an identical prism to $60^{\circ} \mathrm{C}$ at a much slower constant rate of $5^{\circ} \mathrm{C} / \mathrm{h}$. In this case, the maximum expansion was lower, and no contraction was observed, because, as the water expanded, it flowed out of the specimen with little increase in pressure. After it was cooled back to $20^{\circ} \mathrm{C}$, this prism exhibited no permanent length change. The permanent increase in length observed for the rapidly heated specimen indicated either a viscoelastic effect or microcracking within the specimen. Another experiment was conducted by heating a prism slowly to $60^{\circ} \mathrm{C}$ and then cooling rapidly to $20^{\circ} \mathrm{C}$. In this case the sudden increase in the density of the pore fluid on cooling created a compressive force in the specimen, a phenomenon that has been observed and quantified for pure gels. ${ }^{8}$ This experiment resulted in a permanent negative strain of $1.6 \times 10^{-4}$. Because microcracking is less likely to account for a compressive strain in cement paste, this result favors viscoelastic strain as the cause of the length changes.

A useful way to monitor the changes that occur during a heat treatment is to measure the weight of the specimen as the water diffuses out of the specimen. Figure 3 shows the weight of the same prism described by Fig. 2 as a function of temperature: as expected, the weight decreases monotonically. In Fig. 3, the density of water is also plotted on the right hand axis. At lower temperatures, the weight loss and the density of water track closely, but, above $\sim 50^{\circ} \mathrm{C}$, there is a deviation, with more weight loss from the prism than can be accounted for by expansion of the pore fluid. On resaturation, the specimen does not recover its full previous weight, and this permanent weight loss closely reflects the deviation from the density change of water at $60^{\circ} \mathrm{C}$. No permanent length change in the specimen as a result of the heat treatment suggests that the physical properties of cement paste are changed by heat treatment.

A few other experiments were conducted to isolate the source of the weight loss, as summarized in Table II. Specimens were heated slowly to $40^{\circ}$ or $60^{\circ} \mathrm{C}$ and held for $12 \mathrm{~h}$ before they were slowly cooled back to room temperature; the total treatment time was $\sim 24$ $\mathrm{h}$. The weight was monitored for at least 1 week following the experiment, and no weight changes were observed after $1-2 \mathrm{~d}$. One possibility is that aluminate phases in the ordinary portland cement (OPC) pastes, such as ettringite, were decomposing, which caused a decrease in the density of the solid phases. However, white portland cement pastes with a significantly lower aluminate content than the OPC exhibited similar weight losses, as did a single $\mathrm{C}_{3} \mathrm{~S}$ paste specimen, which indicated that the effect resulted from the calcium silicate phases.

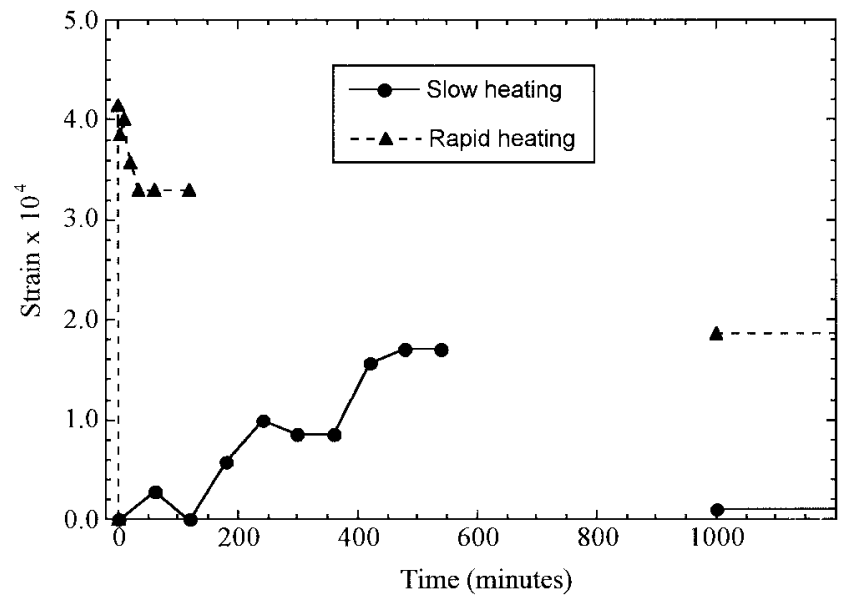

Fig. 2. Length change of a bar heated slowly to $60^{\circ} \mathrm{C}$ and then slowly cooled back to $20^{\circ} \mathrm{C}$ (circles) and replotted data from Fig. 1 (triangles) for rapid heating (note different time scale). 


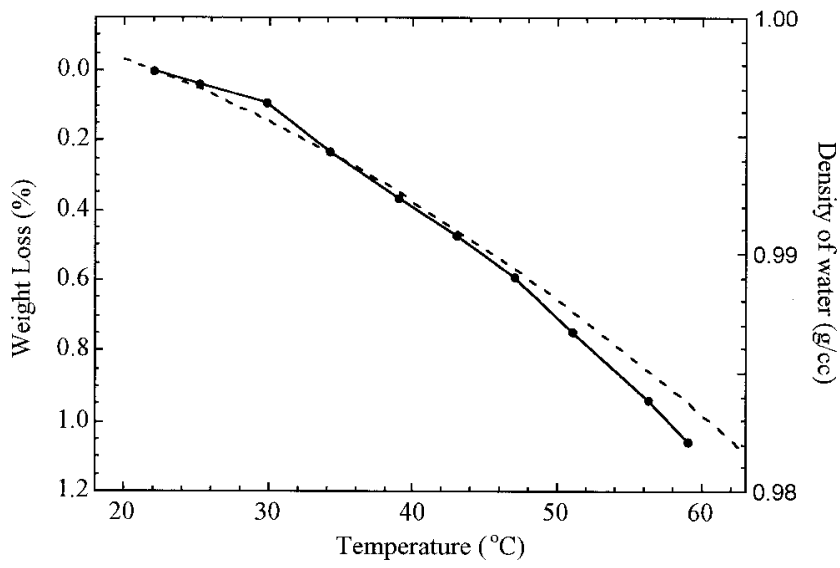

Fig. 3. Weight loss of a slowly heated bar as a function of temperature (filled circles). Density of water is plotted against the right axis (dotted line).

A second possibility is that the pastes underwent leaching of soluble solid phases (such as calcium hydroxide) at high temperatures. This was tested by drying specimens slightly (2\% weight loss) and then sealing them tightly into plastic bags so that no liquid water or water vapor could enter or leave during the heat treatment. As shown in Table II, these specimens also exhibited a permanent weight loss after resaturation in limewater, while control specimens that were dried and resaturated with no heat treatment recovered their original weight, as expected. Finally, pastes were heat-treated to $40^{\circ} \mathrm{C}$. This milder heat treatment did not result in a statistically significant weight change.

The age of the paste affected the results, with younger pastes exhibiting less weight loss. This is likely due to, at least in part, additional hydration of younger specimens during the heat treatment. Binding of water during hydration can increase the saturated weight of cement paste (by allowing additional water to enter the pore system), and this partially offsets the weight loss caused by the heat treatment. The greater amount of C-S-H reaction product present in older, more fully hydrated pastes may also increase their weight loss. The best explanation for the experimental results listed in Table II is that chemical changes in the C-S-H gel phase above $40^{\circ} \mathrm{C}$ cause the observed permanent weight losses. This is related to polymerization of the silicates in the C-S-H gel.

\section{(2) Methanol Exchange}

When saturated cement paste is submerged in methanol, the methanol exchanges with the pore fluid over time via a diffusioncontrolled process. The rate of exchange depends on the specimen

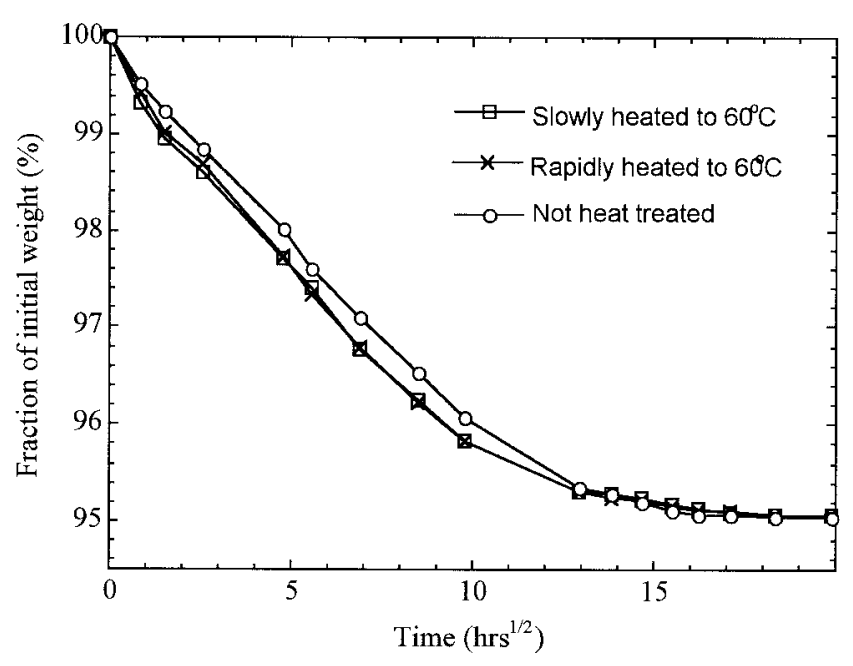

Fig. 4. Methanol exchange of heat-treated bars and an unheated control.

geometry and the pore structure; larger and older specimens and lower $w / c$ ratio pastes require a longer time to finish exchange (see, e.g., Ref. 12). The exchange process can be followed by tracking the weight of the specimen, because methanol is considerably less dense than water $\left(0.79 \mathrm{~g} / \mathrm{cm}^{3}\right)$. The methanol exchange kinetics provides some information about the saturated pore structure, particularly when results from specimens with the same geometry are compared.

Three identical $28 \mathrm{~d}$ old specimens were prepared for methanol exchange as follows: the first was heat-treated by placing it directly into $60^{\circ} \mathrm{C}$ limewater; the second was heated slowly to $60^{\circ} \mathrm{C}$ at a rate of $5^{\circ} \mathrm{C} / \mathrm{h}$; and the third was not heat-treated as a control. After $12 \mathrm{~h}$ at $60^{\circ} \mathrm{C}$, both heat-treated specimens were cooled slowly back to room temperature. All three specimens were then placed into a reservoir of pure methanol, which was refreshed each day during the experiment. As shown in Fig. 4, the percent change in weight after completion of methanol exchange was the same in all cases, which indicated that the volume of porosity accessible to methanol was not changed by the heat treatment. The initial rate of methanol exchange was more rapid for both of the heat-treated specimens as compared with the control, but no difference in the exchange rate was observed at any point for the two heating rates. The initial rate difference indicated that the capillary porosity was increased or made more connected by the heat treatment and that this effect was caused by the increased temperature rather than by the increased pressure inside the paste created by rapid heating. After most of the exchange was complete, the weight of the control specimen was the same as that of

Table II. Weight Change of Pastes Caused by Heat Treatment

\begin{tabular}{clc}
\hline \multicolumn{1}{c}{ Paste type } & \multicolumn{1}{c}{ Treatment } & $\begin{array}{c}\text { Weight change } \\
(\%)\end{array}$ \\
\hline OPC, & $60^{\circ} \mathrm{C}$ for $24 \mathrm{~h}$ in lime water & -0.34 \\
$0.45 w / c, 90 \mathrm{~d}$ old & $60^{\circ} \mathrm{C}$ for $24 \mathrm{~h}$ after drying to $2 \%$ weight loss & -0.40 \\
White cement, & $60^{\circ} \mathrm{C}$ for $24 \mathrm{~h}$ in lime water & -0.25 \\
$0.40 w / c, 42 \mathrm{~d}$ old & $60^{\circ} \mathrm{C}$ for $24 \mathrm{~h}$ after drying to $2 \%$ weight loss & -0.30 \\
& Drying to $2 \%$ weight loss (no heating) & 0.0 \\
OPC, & $60^{\circ} \mathrm{C}$ for 24 h in lime water & -0.19 \\
$0.45 w / c, 14 \mathrm{~d}$ old & $60^{\circ} \mathrm{C}$ for $24 \mathrm{~h}$ after drying to $2 \%$ weight loss & -0.23 \\
& $40^{\circ} \mathrm{C}$ for $24 \mathrm{~h}$ in lime water & -0.02 \\
White cement, & $60^{\circ} \mathrm{C}$ for 24 h in lime water & -0.18 \\
$0.45 w / c, 14 \mathrm{~d}$ old & $60^{\circ} \mathrm{C}$ for $24 \mathrm{~h}$ after drying to $2 \%$ weight loss & -0.17 \\
& $40^{\circ} \mathrm{C}$ for $24 \mathrm{~h}$ in lime water & 0.01 \\
$\mathrm{C}_{3} \mathrm{~S}$, & $60^{\circ} \mathrm{C}$ for $24 \mathrm{~h}$ in lime water & -0.45 \\
$0.40 w / c, 6$ months old & & \\
\hline
\end{tabular}




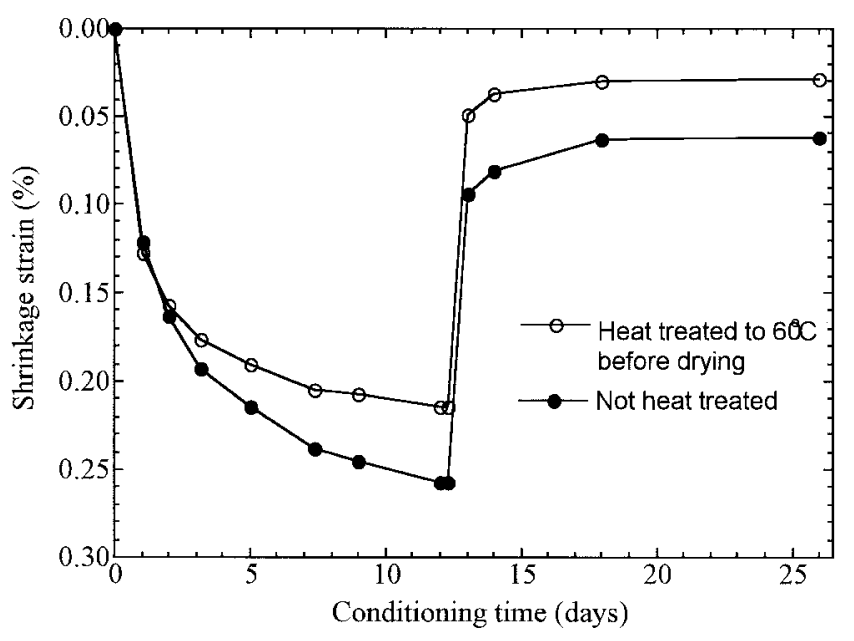

Fig. 5. Shrinkage strain for a prism heat treated at $60^{\circ} \mathrm{C}$ and for an untreated control. Prisms were dried for $12 \mathrm{~d}$ at $50 \% \mathrm{RH}$ and then resaturated in limewater.

the heat-treated specimens, and the total time required to complete the methanol exchange was the same in all cases. Overall, these results suggested that heat treatment at $60^{\circ} \mathrm{C}$ shifted the pore-size distribution, which increased the capillary porosity at the expense of the mesoporosity, but did not change the total pore volume.

\section{(3) Heat Treatment before Drying}

Figure 5 shows the drying shrinkage of two $8 \mathrm{~d}$ old OPC prisms, one of which was heat-treated at $60^{\circ} \mathrm{C}$ for $24 \mathrm{~h}$ before it was dried. The heat-treated prism shrank less on drying and exhibited much less irreversible shrinkage after resaturation. This result is in good agreement with the work of Parrott. ${ }^{4,5}$ Figure 6 shows the weight loss as a function of time for the same two specimens. The heat-treated prism lost weight much more rapidly during the first few days, and then reached an equilibrium weight more quickly, as compared with the control. These weight-loss data, along with the methanol exchange results presented above, strongly support the hypothesis, first suggested by Parrott, ${ }^{4,5}$ that a heat treatment causes a change in the pore-size distribution, which increases the amount of capillary porosity. However, the mechanism for this has not been clearly defined. One possibility is that the expansion of the pore fluid on heating changes the pore structure to make it more connected. However, the weight loss results shown in Fig. 5 did not change depending on the rate of heating-pastes heated

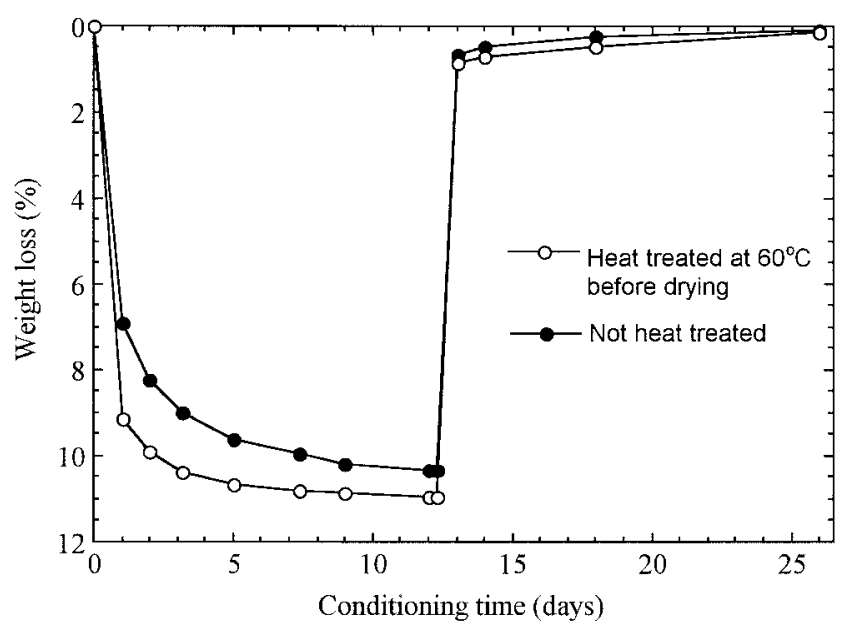

Fig. 6. Weight loss for a prism heat-treated at $60^{\circ} \mathrm{C}$ and for an untreated control. Prisms were dried for $12 \mathrm{~d}$ at $50 \% \mathrm{RH}$ and then resaturated in limewater.

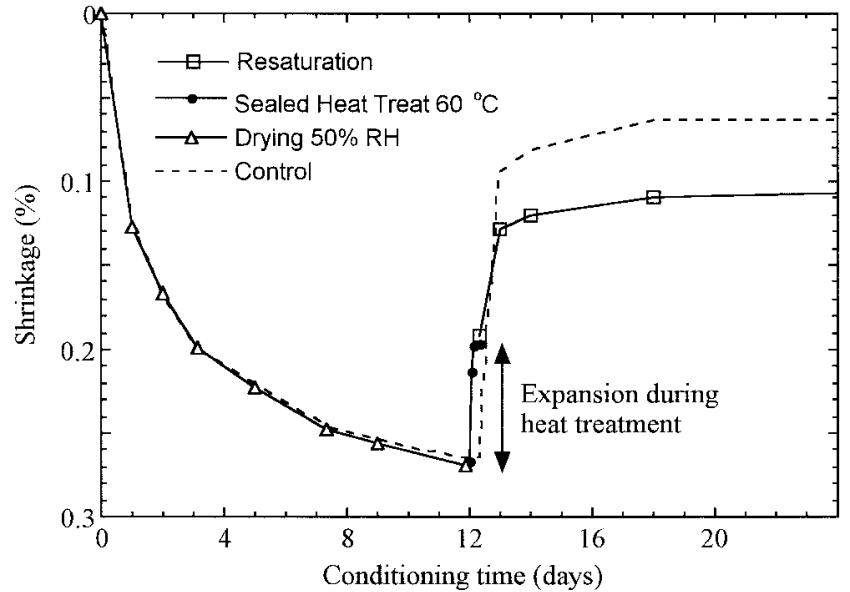

Fig. 7. Length change of a prism that was dried for $12 \mathrm{~d}$ at $50 \% \mathrm{RH}$, heat-treated for $6 \mathrm{~h}$ (while sealed to prevent weight change), and then resaturated. Note the large expansion during the heat treatment and the larger irreversible shrinkage as compared with the control.

very slowly showed the same weight-loss kinetics as pastes heated rapidly. Thus, the change in the pore structure is some type of temperature-induced coarsening.

\section{(4) Heat Treatment after Drying}

When cement paste was heat-treated while in a partially dried state, apparently anomalous behavior was observed. Figure 7 shows the length changes (expressed as percent strain) of an OPC prism that was hydrated for $8 \mathrm{~d}$ under limewater, dried for $12 \mathrm{~d}$ at $50 \% \mathrm{RH}$ and $20^{\circ} \mathrm{C}$, and then heated to $60^{\circ} \mathrm{C}$ in a tightly sealed plastic bag for $8 \mathrm{~h}$. After the heat treatment, the prism was removed from the bag and resaturated in limewater at $20^{\circ} \mathrm{C}$. During the $8 \mathrm{~h}$ heat treatment, the prism was periodically cooled to room temperature for a few minutes to record length and weight. No change in the weight of the bar occurred during the heat treatment, because the sealed plastic bag prevented water from escaping or entering.

As shown in Fig. 7, the bar first underwent normal drying shrinkage during the $12 \mathrm{~d}$ drying period. Then, during the subsequent heat treatment, the bar expanded at a relatively rapid rate, reaching an equilibrium length after 1-2 $\mathrm{h}$ that decreased the net shrinkage by $\sim 25 \%$. Because thermal expansion effects were avoided by making all length measurements at $20^{\circ} \mathrm{C}$, this expansion resulted from a change in the microstructure. The final (irreversible) shrinkage after resaturation at $20^{\circ} \mathrm{C}$ was increased considerably by the heat treatment, as compared with a control that was dried and resaturated without heating (see Fig. 7). This behavior is discussed in the next section.

\section{General Discussion}

The results presented here strongly indicate that a heat treatment at $60^{\circ} \mathrm{C}$ coarsens the microstructure of cement paste. The capillary porosity is increased, leading to more rapid weight loss on drying and more rapid initial exchange with methanol. There is a corresponding decrease in the mesoporosity, as indicated by the later rate of exchange with methanol and by the fact that the total porosity accessible to methanol is not changed. Loss of mesoporosity is also supported by the results of Parrott, ${ }^{4}$ who has observed a decrease in weight loss on drying from $85 \%$ to $55 \% \mathrm{RH}$ after a heat treatment. The smaller shrinkage on drying to $50 \% \mathrm{RH}$ is also consistent with a decrease in mesoporosity, although this also may be due to an increase in the stiffness of the paste. Drying shrinkage at humidity levels above $\sim 45 \% \mathrm{RH}$ is due to capillary tension forces in partially emptied pores. At $50 \% \mathrm{RH}$, the smallest spherical pores that can be theoretically emptied are $\sim 2.5 \mathrm{~nm}$ in 
diameter. ${ }^{2}$ In the experiments performed here, it is unlikely that such small pores were emptied, because drying was not performed to full equilibrium. The smaller drying strains seen after a heat treatment indicate that the number of pores in the size range of $\sim 5-10 \mathrm{~nm}$, which is the mesopore regime, is decreased.

The hydration of $\mathrm{C}_{3} \mathrm{~S}$ at various temperatures is known to change the pore structure, with higher temperatures resulting in a coarser structure and more capillary porosity. Consequently, concrete cured at higher temperatures has a lower strength. Bentur and co-workers ${ }^{13,14}$ have hydrated $\mathrm{C}_{3} \mathrm{~S}$ pastes at $4^{\circ}, 25^{\circ}$, and $65^{\circ} \mathrm{C}$ and have found that the paste hydrated at $65^{\circ} \mathrm{C}$ has a larger capillary pore volume and a correspondingly smaller mesopore volume, when all the pastes are compared at equal degrees of hydration. The paste cured at $65^{\circ} \mathrm{C}$ also has a lower surface area, as measured by gas sorption, and exhibits less shrinkage on drying.

Work performed by Parrott $t^{4,5}$ and the results reported here indicate the interesting result that many of the differences observed in pastes hydrated at high temperatures are also observed when a paste cured at room temperature is exposed to high temperature for a relatively short time. This is significant, because it indicates that there are microstructural changes that occur as a result of heating, rather than simply different microstructures forming at different temperatures for kinetic reasons.

The C-S-H gel phase, to a large extent, controls the permeability, drying and creep behavior, and strength of cement-based materials, and changes in properties due to different hydration temperatures and to heat treatment have long been attributed to changes in the structure of the $\mathrm{C}-\mathrm{S}-\mathrm{H}$ gel. There is important independent evidence for changes to the C-S-H gel on heating, in that the degree of silicate polymerization in the C-S-H phase increases during a heat treatment. ${ }^{5}$ Bentur et al. ${ }^{15}$ have studied creep and drying shrinkage of pure calcium silicate pastes and have concluded that the degree of polymerization of the silicate in the $\mathrm{C}-\mathrm{S}-\mathrm{H}$ has a significant influence on the magnitude of the irreversible creep and shrinkage. Pastes hydrated at higher temperatures and pastes that have been dried have a larger degree of silicate polymerization and are less susceptible to irreversible strains.

To explain the relatively rapid coarsening of the pore structure on heating, leading to increased capillary porosity and less mesoporosity, the most likely hypothesis is a densification of the $\mathrm{C}-\mathrm{S}-\mathrm{H}$ gel phase. The loss of water associated with the C-S-H, which could include tightly adsorbed $\mathrm{H}_{2} \mathrm{O}$ as well as $\mathrm{OH}^{-}$groups, increases the C-S-H density. It is well established that higher hydration temperatures lead to a greater degree of silicate polymerization in $\mathrm{C}-\mathrm{S}-\mathrm{H},{ }^{13,16-18}$ as well as a lower $\mathrm{H} / \mathrm{S}$ ratio. ${ }^{13}$ This polymerization process removes $\mathrm{OH}^{-}$groups, converting them to liquid water through a condensation reaction:

$$
-\mathrm{Si}-\mathrm{OH}+\mathrm{HO}-\mathrm{Si}-\rightarrow-\mathrm{Si}-\mathrm{O}-\mathrm{Si}-+\mathrm{H}_{2} \mathrm{O}
$$

Condensation of the silicates creates linear chains rather than crosslinked structures, ${ }^{17}$ as evidenced by the lack of Q3 groups (silicon bonded to three oxygens), with pentamer and octomer chains forming at the expense of dimers. It is likely that condensation within the C-S-H involves the calcium as well, forming additional $\mathrm{Ca}-\mathrm{O}-\mathrm{Si}$ linkages. ${ }^{19}$ These processes provide a plausible explanation for the permanent weight loss observed for cement paste after a heat treatment (see Table II). Because water has a larger volume in the liquid state than when bound into a solid as $\mathrm{OH}^{-}$groups, condensation reactions exemplified by reaction (1) tend to decrease the bulk density of a specimen. When a saturated cement paste is heat-treated, the external dimensions of the specimen remain the same, and, thus, the excess liquid water simply leaves the specimen at the surface, resulting in a net weight loss. This phenomenon is the reverse of "autogeneous shrinkage," which is the loss of internal water during hydration caused by the increase in density as liquid water is bound into reaction products. Thus, this phenomenon might be thought of as "autogeneous expansion."

The fact that the specimen dimensions are not changed by the heat treatment (outside of thermal expansion effects) indicates that the densification of the C-S-H is restrained by other solid phases, preventing macroscopic shrinkage. This restraint is likely provided by calcium hydroxide crystals, which are closely intermixed with the C-S-H.

Drying cement paste increases the degree of silicate polymerization. ${ }^{15}$ Helmuth and Turk $^{20}$ made an early observation that pastes that were dried and resaturated did not recover the expected amount of weight on resaturation, even when the final change in specimen volume (irreversible shrinkage) was taken into account. The ratio of the volumetric shrinkage to the volume of unrecovered water, which would be unity if the irreversible shrinkage was simply a reduction in the pore volume, was calculated by Helmuth and Turk $^{20}$ to be 0.5 . This means that twice as much water was lost as could be accounted for by the decrease in specimen volume. Parrott and Young ${ }^{21}$ studied the drying behavior of $\mathrm{C}_{3} \mathrm{~S}$ and also found this ratio to be $\sim 0.5$. This discrepancy was explained by suggesting that rearrangement of the pore structure on drying prevented water from fully repenetrating emptied pore space. Because of the current results, it seems more likely that the permanent weight loss after drying and resaturation is a result of the conversion of bound $\mathrm{OH}^{-}$groups in the C-S-H gel phase to liquid water.

The rapid length increase of bars that were heat-treated after partial drying (see Fig. 7) is in good agreement with the hypothesis that there is a change in the pore structure on heating. When the amount of water in a partially dried specimen is held fixed and then the capillary porosity is increased at the expense of the mesoporosity, the average size of the pores containing water menisci increases. As a result, the capillary tension forces that create the drying strain are decreased, and the specimen expands back toward its original (saturated) length. This effect is compounded by the generation of additional liquid water from the $\mathrm{C}-\mathrm{S}-\mathrm{H}$ gel during the heat treatment, as discussed earlier. The release of liquid water in a partially dried cement paste also relieves the capillary tension by filling the small pores. Thus, it is likely that the change in the pore structure and the release of liquid water are responsible for the large expansion during heating of dried paste.

The effect of heat treatment on irreversible shrinkage also provides important clues to the chemical and microstructural changes that occur. An increase in the silicate bonding within the $\mathrm{C}-\mathrm{S}-\mathrm{H}$ phase, which results from heat treatment and drying, makes the C-S-H stiffer and less susceptible to permanent deformation. Thus, when a paste is heat-treated before it is dried and resaturated, the irreversible shrinkage is significantly less than a non-heattreated control. Likewise, a paste that has been dried and resaturated exhibits much less irreversible shrinkage when dried a second time. ${ }^{2}$ When the paste is heated in the dry state (see Fig. 7), the shrinkage caused by capillary tension is "locked in" by the additional silicate bonding, and the paste does not return to its previous length when the capillary forces are removed. The results presented here are in good agreement with the hypothesis of Bentur et al., ${ }^{15}$ who have proposed that irreversible shrinkage in older pastes is caused by additional silicate bonds in the C-S-H component.

A limited number of experiments have been performed using $40^{\circ} \mathrm{C}$ heat treatments, and little or no effect has been observed. This is in agreement with the established belief that the chemical and physical structures of cement are not significantly affected by curing temperatures below $\sim 45^{\circ} \mathrm{C}^{2}$

\section{Conclusions}

The length and weight of cement paste specimens were monitored during a variety of experiments involving heating to $60^{\circ} \mathrm{C}$ and drying. The effects of heating on cement paste could be separated into two distinct categories: those that result from the large thermal expansion coefficient of liquid water and those that result from temperature-induced microstructural changes to the $\mathrm{C}-\mathrm{S}-\mathrm{H}$ gel phase. The focus of this study was on the latter. 
Therefore, measurements associated with the following observations were all taken at room temperature, even when the observation being described occurred during heating.

Application of a relatively brief $60^{\circ} \mathrm{C}$ heat treatment to mature, saturated cement paste has the following effects:

(1) Subsequent total shrinkage on drying to $50 \% \mathrm{RH}$ is decreased.

(2) Subsequent irreversible shrinkage on drying to $50 \% \mathrm{RH}$ is significantly decreased.

(3) Subsequent rate of weight loss on drying to $50 \% \mathrm{RH}$ is increased.

(4) Subsequent rate of methanol exchange is increased initially, but the total time required for full exchange and the final weight change after exchange are unchanged.

(5) The saturated weight of the specimen is decreased by a small but measurable amount. This observation is reported here for the first time.

Heating cement paste to $60^{\circ} \mathrm{C}$ while in a partially dry state has the following effects:

(1) The specimen undergoes a rapid expansion, regaining a significant fraction of the length change caused by drying. This effect is unrelated to thermal expansion.

(2) The irreversible shrinkage after resaturation is greatly increased. This observation is reported here for the first time.

These apparently disparate observations can be explained by a densification of the C-S-H gel phase on heating, caused by a decrease in the C-S-H bound water content and an increase in the degree of silicate polymerization. This densification coarsens the pore structure of the paste, increasing the capillary porosity at the expense of the mesoporosity, and stiffens the C-S-H, making it more resistant to collapse or deformation. Densification also releases liquid water from the solid C-S-H.

\section{References}

${ }^{1}$ J. J. Thomas and H. M. Jennings, "Effect of $\mathrm{D}_{2} \mathrm{O}$ and Mixing on the Early Hydration Kinetics of Tricalcium Silicate," Chem. Mater., 11, 1907-14 (1999).

${ }^{2}$ S. Mindess and J. F. Young, Concrete; p. 305. Prentice Hall, Englewood Cliffs, NJ, 1981.
${ }^{3}$ M. Mouret, A. Bascoul, and G. Escadillas, "Drops in Concrete Strength in Summer Related to the Aggregate Temperature," Cem. Concr. Res., 27, 345 (1997). ${ }^{4}$ L. J. Parrott, "Basic Creep, Drying Creep, and Shrinkage of a Mature Cement Paste after a Heat Cycle," Cem. Concr. Res., 7, 597 (1977).

${ }^{5}$ L. J. Parrott, "Recoverable and Irrecoverable Deformation of Heat-Cured Cement Paste," Mag. Concr. Res., 29, 26 (1977).

${ }^{6} \mathrm{~S}$. Sabri and J. M. Illston, "Immediate and Delayed Thermal Expansion of Hardened Cement Paste," Cem. Concr. Res., 12, 199-208 (1982).

${ }^{7}$ H. Ai and J. F. Young, "Volume Stability of Densified Cement Pastes"; pp. 493-507 in Materials Science of Concrete-The Sidney Diamond Symposium. Edited by M. Cohen, S. Mindess, and J. Skalny. American Ceramic Society, Westerville, $\mathrm{OH}, 1998$.

${ }^{8}$ G. W. Scherer, H. Hdach, and J. Phalippou, "Thermal Expansion of Gels: A Novel Method for Measuring Permeability," J. Non-Cryst. Solids, 130, 157-70 (1991).

${ }^{9}$ G. W. Scherer, "Structure and Properties of Gels," Cem. Concr. Res., 29, 1149-57 (1999).

${ }^{10} \mathrm{G}$. W. Scherer, "Thermal Expansion Kinetics: Method to Measure Permeability of Cementitious Materials: I, Theory," J. Am. Ceram. Soc., 83, 2753-61 (2000).

${ }^{11}$ H. Ai, J. F. Young, and G. W. Scherer, "Thermal Expansion Kinetics: Method to Measure Permeability of Cementitious Materials: II, Application to Hardened Cement Pastes," J. Am. Ceram. Soc., 84, 385-91 (2001).

${ }^{12}$ L. J. Parrott, "Effect of Drying History on the Exchange of Pore Water with Methanol and upon Subsequent Methanol Sorption Behavior in Hydrated Alite Paste," Cem. Concr. Res., 11, 651 (1981).

${ }^{13}$ A. Bentur, R. L. Berger, J. H. Kung, N. B. Milestone, and J. F. Young, "Structural Properties of Calcium Silicate Pastes: II, Effect of Curing Temperature," J. Am. Ceram. Soc., 62, 362-66 (1979).

${ }^{14} \mathrm{~A}$. Bentur, "Effect of Curing Temperature on the Pore Structure of Tricalcium Silicate Pastes," J. Colloid Interface Sci., 74, 549-60 (1980).

${ }^{15}$ A. Bentur, R. L. Berger, F. V. Lawrence Jr., N. B. Milestone, S. Mindess, and J. F. Young, "Creep and Drying Shrinkage of Calcium Silicate Pastes III. A Hypothesis of Irreversible Strains," Cem. Concr. Res., 9, 83-96 (1979).

${ }^{16}$ J. Hirljac, Z. Q. Wu, and J. F. Young, "Silicate Polymerization During the Hydration of Alite," Cem. Concr. Res., 13, 877-86 (1983).

${ }^{17}$ J. F. Young, "Investigations of Calcium Silicate Hydrate Structure Using Silicon-29 Nuclear Magnetic Resonance Spectroscopy," J. Am. Ceram. Soc., 71, C-118-C-120 (1988).

${ }^{18}$ H. Ishida, K. Sasaki, Y. Okada, and T. Mitsuda, "Highly Reactive $\beta$-Dicalcium Silicate: III, Hydration Behavior at $40^{\circ}-80^{\circ} \mathrm{C}, " \mathrm{~J}$. Am. Ceram. Soc., 75, 2541-46 (1992).

${ }^{19} \mathrm{X}$. Cong and R. J. Kirkpatrick, "Effects of the Temperature and Relative Humidity on the Structure of C-S-H Gel," Cem. Concr. Res., 25, 1237-45 (1995).

${ }^{20}$ R. A. Helmuth and D. H. Turk, "The Reversible and Irreversible Drying Shrinkage of Hardened Cement Paste and Tricalcium Silicate Pastes," Journal of the Portland Cement Association R\&D Laboratories, [May] 8-21 (1967).

${ }^{21}$ L. J. Parrott and J. F. Young, "Shrinkage and Swelling of Two Hydrated Alite Pastes"; pp. 25-48 in Fundamental Research on Creep and Shrinkage of Concrete. Edited by F. H. Wittmann. Martinus Nijhoff, Boston, MA, 1982. 